\title{
Analysis of Interpersonal Communication Processes in Digital Factory Environments
}

\author{
Jens Schütze ${ }^{1}$, Heiko Baum ${ }^{1}$, Martin Laue ${ }^{2}$, and Egon Müller ${ }^{1}$ \\ ${ }^{1}$ Chemnitz University of Technology, Institute of Industrial Management and Factory Systems, \\ Department of Factory Planning and Factory Mangement \\ 09107 Chemnitz, Germany \\ \{jens.schuetze, heiko.baum, egon.mueller\}@mb.tu-chemnitz.de \\ ${ }^{2}$ Volkswagen AG, Department of Production Development (PKP-K/I) \\ 38436 Wolfsburg, Germany \\ martin.laue@volkswagen.de
}

\begin{abstract}
The paper outlines the scope of influence of digital factory on the interpersonal communication process and the exemplary description of them. On the basis of a brief description about the theoretical basic concepts of the digital factory occurs the illustration of communicative features in digital factory. Practical coherences of interpersonal communication from a human oriented view were analyzed in Volkswagen AG in Wolfsburg in a pilot project. A modeling method was developed within the process analysis. This method makes it possible to visualize interpersonal communication and its human oriented attribute in a technically focused workflow. Due to the results of a developed inquiry about communication analysis and process models of modeling methods it was possible to build the processes in a suitable way for humans and to obtain a positive implication on the communication processes.
\end{abstract}

Keywords: Digital factory, Human communication, Business process modeling, Collaborative networks, Social network analysis.

\section{Introduction}

Most major carmakers, including Daimler AG, BMW AG, General Motors Corp., Ford Motor Co. and Toyota Motor Corp., investing billions of dollar in digital factory solutions. Using sophisticated design and manufacturing tools, engineers should be able to determine before production, whether a car part is going to fit into a vehicle as planned or whether a weld point can be placed as expected [1]. Improvement in all essential factory processes is a further anticipated benefit from the digital factory [2].

Volkswagen Group, which reported in the year 2008 sales totaling €113.8 billion, noticed recently an unwanted side effect of integrated digital concepts. While implementing digital manufacturing planning in their main plant in Wolfsburg (Germany) social aspects were left unconsidered. When Volkswagen implemented more and more digital factory applications the interpersonal communications were reduced. The fact was known and wanted, because the 'digital' communication (Communication between technical devices) is considered more accurate and less error-sensitive than 
the 'analog' communication (Human communication, no matter if face-to-face or media-mediated). This approach was successful in many departments, but not completely. In some cases, the reduction of communication options led to coordination problems in certain business processes. Some major issues identified in communication processes were due to interruption and malfunctioning. It was not expected that interpersonal communications plays such an important role in a strong hierarchical environment. Volkswagen in Wolfsburg decided to start the research project 'HoSeKo' together with Chemnitz University of Technology to analyze the role of interpersonal communication processes in digital factory environments, to identify main influencing factors in order to develop best practice concepts and workflows.

\section{Corresponding Base Concepts}

Digital Factory. According to Guideline \#4499 of the Association of German Engineers [3] the digital factory is the generic term for a large network of digital models, methods and tools (for e.g. simulation and 3D visualization) which are integrated through an unified data management. The digital factory's function is the planning, realization, supervision and permanent improvement of all essential factory processes and resources in association with the product. The key elements of the present digital factory approach in relation to communication are: (a) Reduction of interpersonal communication by automation. (b) Intuitive access to complex cases by multimedia support. By this 'a digital factory represents a persistent hybrid community where a rich virtualized environment demonstrating a variety of factory activities will facilitate the sharing of factory resources, manufacturing information and knowledge and help the simulation of collaborative design, planning, production and management among different participants and departments' [4].

Communication. Communication is a complex and polymorphic process. Even if it is commonly understood as 'a process by which information is exchanged between individuals through a common system of symbols, signs, or behavior' [5] there are at least 126 [6] or even 160 [7] different definitions of this term's existence. A number of models and theories attempt to explain this phenomenon [8]. The main object of communication is considered as understanding between individuals and collaboration.

Collaborative Network. The term of a Collaborative Network (CN) is usually defined as 'variety of entities (e.g. organizations and people) that are largely autonomous, geographically distributed, and heterogeneous in terms of their operating environment, culture and goal' [9]. Another commonly used definition ('Collaborative network is a set of participants who would like to work together in respond to one or multiple common goals and a set of relationships between the participants.' [10]) understands the $\mathrm{CN}$ term in a wider sense. Autonomy, geographical distribution and heterogeneity are no explicit prerequisites to form a $\mathrm{CN}$. Based on the second point of view, individuals from a strong hierarchical environment such as a multi-national company could be perceived as $\mathrm{CN}$ too, if they 'work together in respond to one or multiple common goals' as long as the collaborative aspect is essential. The discussion about theoretical foundations and possible forms of $\mathrm{CN}$ is still going on $[11,12]$. 
Social Network Analysis. Beginning of the 1950s social network analysis (SNA) has emerged as a key technique in several scientific areas, i.e. sociology, biology, information science, organization science and others [13]. SNA is usually being associated with certain metrics, like degree centrality, betweenness centrality, closeness centrality or eigenvalue. For analyzing qualitative aspects of networks, other methods are more appropriate.

\section{Digital Factory and Communication}

Digital factory tools are used as technical work equipment to process a task. By this they can play different roles in the communication process. On the base of the Lasswell formula of communication [14] different roles of the digital factory are possible:

Digital Factory as Actor. Digital factory systems can work as sender or receiver of communication. Communication is possible (a) among digital factory systems or (b) between digital factory systems and humans. In case (a) the compatibility of data formats between the used systems has to be ensured. In case (b) the most important factor is operation of Human-Machine Interface (HMI).

Digital Factory as Medium. Especially in the area of production planning Data Management Systems (DMS) and Workflow Management Systems (WfMS) are used as communication medium. DMS are primarily used for storage, documentation and exchange of data. A special case is Knowledge Management Systems (KMS), which offers support for creation, organization, capture, storage and dissemination of information. In contrast to what WfMS provides completely or partially automated support for workflows, in which information, data or documents are passed on from one employee to the other.

Digital Factory as Message. The use of digital factory systems can influence the message or how the message is understood by humans. One explanation could be the phenomenon described in Channel Reduction theory [15]. Moreover, the communication context (Situation, chosen communication channel, etc.) is influencing the message and leading to distortions.

\section{Case Study: Production Planning Workflow}

Concrete implications of the digital factory on the communication process as a medium of communication will be explained in greater detail using the example of Volkswagen. The example displays a workflow already implemented in the production planning. The workflow concept is supposed to help the organization to achieve its aims, such as the reduction of work proceeding time, an improved transparency and documentation with an enhancement of the proceeding quality.

Problem. The workflow described here supports automatically the coordination of any change requests within production planning prior to their transfer to the Production Development Department in the field of Research and Development (R\&D). 
Products cannot be modified anymore while running through the manufacturing process. The internal production plan execution is necessary to coordinate the implications of change requests of a trade on the manufacturing processes for the other trades. For this purpose, a production planner is sending his change request to his representatives of each trade via a workflow system. During a first phase, the representatives can comment on this change request in case they feel that their manufacturing processes will be concerned. During the second phase, the planner is sending the change requests to each trade again after considering all comments and impulses. At this point, the trades have the following three possibilities to classify themselves: (a) Not being concerned (b) Approving the change request or (c) Rejecting the change request. In case of a rejection, the planner has the possibility to re-send the change request into the workflow system, which means that the whole process will be taken up again. After all trades have either approved the change or have classified themselves as not being concerned, a person responsible of the project has to endorse the change request as well. However, his approval depends on specific premises being formerly settled, such as the amount of investments. After the internal agreement and the planner's approval, the change request will be sent to the Department of Production Development, which will decide about the production changes in the end.

This workflow system showed that a reduction in work proceeding time and an improvement of transparency could be reached. Moreover, managers and leaders are now updated about the current situation for change requests of certain products due to some monitoring data. All completed and hence documented plans to change a product provide valuable experience for future projects. However, there are still some problems regarding communication during this workflow process: Before the creator enters a change request into the workflow system, it is advisable to agree on the feasibility of the product change with the Department of Production Development responsible, as the change request can be rejected after the workflow run. An initial agreement could save the trades time and works, since they have to approve the change, too. Although, this agreement process was a common procedure prior to the introduction of the workflow, it is not regularized in the workflow and not practiced by some production planners anymore. This could be because the new production planners do not know anything about such agreement processes. This case shows clearly the lacking regularization of parallel communication processes in the workflow concept which are not identified as a core process. On the other hand, it displays the production planners' altered attitude towards work routine through the introduction of the workflow. The planner has the impression that his amount of work becomes less after the introduction of the workflow. The effort of one's own work influences the expectation and the perceived justice of the result. This, in turn, has an impact on one's satisfaction. Consequently, it is likely that one will not seem that dissatisfied about a possible rejection by the R\&D. Thus, the planner does not seem as motivated as he used to be after the introduction of the workflow. The planner's aim to achieve a positive result and to exploit all necessary means seem to have become less important. If the parallel communication processes in the workflow had been regularized, the problem would have been to select the appropriate medium of communication for this process. The following case is supposed to illustrate this fact.

During a workflow process lack or conflict-laden communication between the production planner and the representatives of the trades may appear. Prior to the 
introduction of the workflow the planner had to agree with each trade when changing a product. All suggestions for each trade were considered and incorporated into the change request. For this, all representatives of the concerned trades met to agree on the change. It is quite salient that some impulses and comments given by the representatives of the trades from the first phase are not considered. Hence, the change request will be sent unchanged to the second phase where it is commonly rejected. Moreover, it can be observed that agreements conveyed medially are sometimes rather conflict-filled and not always held in a friendly way. A medial transmission enables the planner to decide anonymously. This communication via computer and the resulting anonymity can lead to an anti-social behavior. This latter fact is substantiated by territorial-minded employees. Territorial-mindedness describes the positive attitude towards co-workers of one's own department and the mistrustful and biased attitude towards co-workers of other departments. Moreover, as computer is a technical device, persons communicate without perceiving any sense in comparison to any personal conversation. Thus, computer-mediated communication can lead to a rather deficient and impersonal communication which makes statements and comments difficult to interpret. Generally-speaking, communicating via computer makes the conversation 'unreal' as one is talking to a machine. This can further support tendencies of estrangement and isolation between colleagues as well as an increasing inability to solve conflicts.

Solution. The biggest potentialities to improve interpersonal communication in digital factory are to influence the system development in the analytical phase. The analytical phase of the system development is divided into the conduction of a so called actual analysis and creation of the target concept. Some influencing factors on the communication process are embedded into the Man-Technology-Organization approach (MTO). The general target of the system development is to support a working task on a system-technological basis. Therefore, the targets adapt themselves towards the business objectives from a technical as well as organizational point of view. The aim of the workflow management is to reduce the time for information flow, to increase process transparency and to avoid the storage of redundant data. All the targets which are set by the process management and which can be reached by a systemtechnological support are the following: Process documentation, Creation of flexible processes in order to react quickly to organizational changes as well as Process standardization. Certain objectives like 'How to accomplish a task?' and 'How to support these on a system-technological basis?' are hardly considered in current system development processes. Tasks which are oriented towards human strengths do not have to oppose the business objectives. Employees' competences can be maintained, encouraged and better used by creating human-oriented tasks. The so called Contrastive Task Analysis [16] can be understood as a tool which aims at improving communication as well as using and encouraging human competences. The criteria of the Contrastive Task Analysis are to be considered when analyzing and setting up the task. The human-oriented system development aims at improving the communication between the employees to meet their needs and qualifications. The system further supports individual's personality so that they can fully develop their potentialities and competences. The digital factory as a Workflow Management System is supposed to face possible problems in the interpersonal communication process. Hence, it was 
suggested to influence the system development in the analytical phase by using the MTO approach. The following approaches aim at analysing and improving the communication. They can either be integrated into the Contrastive Task Analysis or conducted as independent measures.

The so called 'Task-Oriented Media Choice' is a method to find an adequate communication medium [17]. It could be integrated into the contrastive task analysis within the human criteria 'communication'. This method links the task-related demands to the appropriateness of a medium in terms of the criteria of accuracy/ability in documentation, rapidness/convenience, privacy and complexity. Thus, the media to be applied is determined by the degree of task structuring and the need of social presence. Hence, an e-mail would be suitable for messages which should be sent, documented and stored in an error-free way. Personal communication, on the other hand, is preferable when conveying complex issues, since Non-Verbal Communication can be easily understood. As a consequence, it is advisable to think about the usefulness of making all communicative task activities within system development automatic. It should be taken into account that complex and difficult contents are conveyed more easily while interacting personally in the workflow. Creating a trustful and an anxiety-free atmosphere in the organization should help to improve interpersonal relationships. At this point, it becomes quite clear how strong interpersonal relationships are intertwined within the organizational culture. Executives are able to influence the following aspects to a certain extent: positioning, strategy, structure, form and selection of personnel of the organization. These parameters could be analyzed in the Contrastive Task Analysis while framing the organizational unit.

However, the staff's communicative behavior is so far found more difficult to be described. Nevertheless, according to the analysis of the organizational culture as well as the personnel's motivation and attitudes, some behavioral suggestions can be drawn. Managers and their way of behaviors are assigned with a symbolic role here owing to their role model functioning. The executives and managers are also responsible for observing and dealing with co-worker's possible misbehavior. In this case, the manager could either talk to the employee or provide training courses to enhance communicational skills. In order to achieve a change in the employee's mind, the manager should appear trustworthy. He should have powers and be able to apply measures to reward or penalize the staffs. The employees of the various departments have to realize that certain differences between them and other departments do exist. They need to accept other person's attitudes in order to oppose territorial-mindedness and co-operational and communicational barriers. Therefore, it is advisable to create certain conditions for interdisciplinary teams, which leave an ample scope to achieve one's own aim in every field. If this is not the case, cooperation barriers resulting from competing interests will arise. Another important aspect is the protection of the employee's own identity which can be secured by clearly restricting the area of competence. The organization may also reward a successful communication between persons, which the interdisciplinary team can consider as a common challenge. Thus, if employees of different fields conduct some aspects of a task together, they will create a common base of experience, create mutual confidence and reach a better understanding. 
Informational meetings are suitable qualification measures to support cooperation and communication across the different fields. These meetings should deal with issues related to cooperation by means of concrete situations. Such training courses ideally take place prior to a development process of a team or as a regular event. They can help to improve the communication between participants of different fields. Another crucial point is that, such a kick-off meeting can oppose anonymity. The participants would have the opportunity to meet each other and to represent their tasks and roles in this project. In line to this, the rules and norms related to the common cooperation and communication could be set up right at the beginning. The kick-off meeting serves to settle targets, to make fixed appointments to define responsibilities as well as to create a base for common teamwork. If all these aspects come into existence, quality effects in the interdisciplinary groups can be expected particularly with long-term, continuous team development processes.

\section{Conclusions}

It is fair to say that the consideration of interpersonal communication processes in digital factory environments is essential for collaborative work tasks. The largest potential for improvement can be located at the design or selection phase of the digital factory solutions.

The two most important analysis results of the workflow are: (a) Practically, a pure technically focused approach dominated. (b) Deficient visualization possibilities of such processes are available. The actual aspects of interpersonal communication and their exemplary image were not discussed practically till now. The solution of examining interpersonal communication was found through the inquiry developed in the project 'HoSeKo'. This inquiry analyzed the information flow, the relation quality and human criteria. In addition to that, a graphical modeling technique was created for the visualization of such processes. This visualization enables building important magnitudes that are analyzed in the inquiry in a suitable form. Furthermore, it was possible to submit those visualized processes of multi-personal discussion. The discussions were required for the localization of the improvement potentials. The specification of interpersonal communication in an IT-supported process of the digital factory should be given more attention from researchers in the future.

Acknowledgments. This paper is mainly based on work performed in the projects 'HoSeKo' (Joint research project between Volkswagen AG, Germany and Chemnitz University of Technology) and 'Me2Co' (Funded by the German Federal Ministry of Education and Research, Reference No. 01 IS C37).

\section{References}

1. Cunha, P.F., Maropoulos, P.G. (eds.): Digital Enterprise Technology: Perspectives and Future Challenges. Springer, New York (2007)

2. Neil, S.: The digital factory. Managing Automation 22(10), 20-27 (2007) 
3. VDI4499, Digital factory: Fundamentals. VDI-Richtlinie 4499 [Guideline of the Association of German Engineers]. Blatt 1 [Part 1]. Ausg. deutsch/englisch [Issue German/English]. Düsseldorf: Beuth (2008)

4. Sacco, M., Redaelli, C., Constantinescu, C., Lawson, G., D'Cruz, M., Pappas, M.: DIFAC: Digital Factory for Human Oriented Production System. In: Jacko, J.A. (ed.) HCI 2007. LNCS, vol. 4553, pp. 1140-1149. Springer, Heidelberg (2007)

5. Merriam-Webster. Communication: Definition from the Mirriam-Webster Online Dictionary (2009),

http: / /www.merriam-webster.com/dictionary/communication (retrieved on March 18, 2009)

6. Dance, F.E.X., Larson, C.E.: The Functions of Human Communication: A Theoretical Approach. Holt, Rinehart and Winston, New York (1976)

7. Merten, K.: Kommunikation: Eine Begriffs- und Prozeßanalyse [Communication: An Analysis of Term and Process]. Westdeutscher Verlag, Opladen (1977)

8. Schütze, J.: Modellierung von Kommunikationsprozessen in KMU-Netzwerken: Grundlagen und Ansätze [Modeling of Communication Processes in SME Networks: Fundamentals and Approaches]. Gabler, Wiesbaden (2009)

9. Camarinha-Matos, L.M., Afsarmanesh, H.: Collaborative Networks: A New Scientific Discipline. Journal of Intelligent Manufacturing 16(4), 439-452 (2005)

10. Rajsiri, V., Lorré, J.P., Bénaben, F., Pingaud, H.: Collaborative Process Definition using an Ontology-based Approach. In: Camarinha-Matos, L.M., Picard, W. (eds.) Pervasive Collaborative Networks. IFIP International Federation for Information Processing, vol. 283, pp. 205-212. Springer, Boston (2008)

11. Camarinha-Matos, L.M., Afsarmanesh, H.: Collaborative Networks: A new scientific Discipline. In: Camarinha-Matos, L.M., Afsarmanesh, H., Ollus, M. (eds.) Virtual Organizations: Systems and Practices, pp. 73-80. Springer Science + Business, Boston (2005)

12. Müller, E. (ed.): Competence-cell based Networks: Theories, Models, Methods and Tools. Springer, London (2009)

13. Freeman, L.C.: The development of social network analysis: A study in the sociology of science. Empirical Press, Vancouver (2004)

14. Lasswell, H.D.: The structure and function of communication in society. In: Bryson, L. (ed.) The communication of ideas: A series of addresses, pp. 37-52. Institute for Religious and Social Studies, New York (1948)

15. von Mettler-Meibom, B.: Kommunikation in der Mediengesellschaft. Tendenzen, Gefährdungen, Orientierungen [Communication in media society: Tendencies, dangers, orientations]. Ed. Sigma, Berlin (1994)

16. Dunckel, H., Pleiss, C. (eds.): Kontrastive Aufgabenanalyse: Grundlagen, Entwicklungen und Anwendungserfahrungen [Contrastive Task Analysis: Fundamentals, Developments and Experiences from Application]. vdf Hochschulverlag der ETH Zürich, Zürich (2007)

17. Reichwald, R., Kathrin, M.: Management und Technologie [Management and Technology]. In: von Rosenstiel, L., Regnet, E., Domsch, M. (eds.) Führung von Mitarbeitern: Handbuch für erfolgreiches Personalmanagement [Leading of Employees: Handbook for Successful Human Resource Management], 5th edn., Schäffer-Poschel, Stuttgart (2003) 